\title{
EM NOME DO OUTRO: REFLEXÕES SOBRE AS IDEIAS DE SKLIAR
}

\section{ON BEHALF OF THE OTHER: REFLECTIONS ABOUT SKLIAR'S IDEAS}

\author{
Simone Guerra Maia ${ }^{59}$
}

\begin{abstract}
Resumo
Há tempos, Carlos Skliar vem se dedicando às questões da inclusão, da alteridade, da mesmidade, do outro, principalmente sobre os aspectos socioantropológicos e histórico-cultural. Neste artigo, pretende-se, em uma pesquisa bibliográfica, discutir as ideias do autor, em uma abordagem qualitativa. Não pretendemos, aqui, esgotar o assunto, pois acreditamos que este estudo seja um convite àqueles que, de alguma forma, sintam-se afetados pela inclusão.
\end{abstract}

Palavras-chave: Carlos Skliar. Outro. Inclusão.

\begin{abstract}
For a long time, Carlos Skliar has been dedicating himself to the matters of inclusion, otherness, sameness, specially about the socio-anthropological and historical-cultural aspects. In this article, it is intended, in a bibliographic research, discuss the author's ideas, in a qualitative approach. We do not intend here to deplet the subject, since we believe this study to be an invitation to those who, somehow, feel affected by inclusion. Keywords: Carlos Skliar. Other. Inclusion.
\end{abstract}

\footnotetext{
${ }^{59}$ Mestranda em Educação pela Universidade Católica de Petrópolis; Diretora Escolar; professora simoneguerra@yahoo.com.br; 0000-0002-7858-1226
} 


\section{RevistAleph}

\section{Introdução}

O objetivo deste artigo é apresentar uma reflexão sobre as ideias de Carlos Skliar sob o ponto de vista dos paradigmas da inclusão, traçando uma análise sobre seus pensamentos entre o binômio inclusão/exclusão; identidade e diferenças, priorizando o discurso e as práticas em torno dos "outros", das alteridades e da escuta. É necessário, neste momento, conhecermos um pouco mais sobre esse autor, que fornece a base para toda a construção deste artigo.

Carlos Bernardo Skliar é argentino, nascido em 1960, possui graduação e especialização em Fonoaudiologia, tem doutorado em Ciências Humanas e pósdoutorado em Educação Especial pela Universidade Federal do Rio Grande do Sul (UFRGS). Pesquisador independente do Conselho Nacional de Pesquisa Científica e Tecnológica da Argentina e professor pesquisador da Facultad Latinoamericana de Ciencias Sociales (FLACSO) na Argentina.

Skliar é um grande pesquisador da área da Educação Especial, principalmente a surdez, sua visão parte de um conceito sócio antropológico e histórico-cultural. Ele se debruçou sobre o ato educativo na Educação Inclusiva.

No que diz respeito aos aspectos socioantropológicos, Skliar ressalta o conceito de normalidade e deficiência sob o ponto de vista dos fenômenos socialmente construídos, partindo das ideias de Foucault que, em seus estudos, defendia uma ética que resguardasse e respeitasse as diferenças em lugar de apenas suprimi-las em defesa de um modelo universal (MARQUES et al., 2009). Skliar se distancia de um modelo clínico-terapêutico e, embora seja fonoaudiólogo de formação, ancora-se também nas abordagens histórico-culturais, inquietando-se para uma possibilidade de acesso real aos deficientes, que são privados culturalmente. Essa possibilidade é firmada em uma relação de escuta e de pequenos gestos que, para o autor, seria o início de uma verdadeira inclusão.

Assim, a presente pesquisa tem uma abordagem qualitativa, e os dados foram obtidos por meio de uma pesquisa bibliográfica, a partir dos livros e artigos citados no Currículo Lattes de Carlos Bernardo Skliar, além de entrevistas e vídeos. 


\section{RevistAleph}

Discutiremos, neste estudo, em maior proporção, a questão do "outro", de quem é esse outro e "com" esse outro, cuja premissa é a de relacionar-se com seus outros. Nas palavras de Skliar (2015):

A olhar sem julgamento, nem condenação prévia, a olhar para a possibilidade de outras existências diferentes da nossa, a fazer uma saudação disponível, a dar as boas vindas, a perguntar, a dar vazão, a permitir, a possibilitar, a deixar fazer, a dar o eu fazer, a sugerir, a conversar etc. (SKLIAR, 2015, p. 27).

Devemos começar a "fazer" inclusão em pequenos gestos e por meio do que Skliar (2015) chama de "gestualidade mínima, sem estridências", em que seremos capazes de pensar no outro sem tentar colocá-lo em uma mesmidade que corrobora para alteridades, sem querer falar pelo outro, sem dar ouvido a sua voz, a sua fala. Buscamos, em nossas discussões, encontrar professores e professoras dispostos a praticar uma escuta pedagógica para o diálogo.

Discorreremos, a seguir, sobre que "outro" é esse que nos é apresentado, ocultado pela deficiência, que o rotula, que o destaca e o põe em evidência perante os outros, em um movimento quase maléfico de fazê-lo se enquadrar como os demais. De quem estamos falando? Quem é esse outro?

\section{Que "outro" é esse?}

Entre 40 crianças, há aquele que ninguém vê, aquele lá atrás da sala, que se joga no chão, que rola entre as carteiras da sala de aula, no recreio ninguém chega perto, afinal, ele "baba" muito, "rouba" todos os biscoitos, fica pulando e batendo palmas do nada, aquele que não entende ninguém e que parece não prestar atenção na professora. Ei! Quem é você?

Por que não entendemos quem é esse menino ou menina que nos é diferente, que nem nos olha, mas sabe que alguém está ao seu lado? Esse outro que enxergamos diferente de nós mesmos, porque não conseguimos fazer com que ele se comporte como os outros 39 (trinta e nove), que se sentam e leem suas lições sem questionar, 


\section{RevistAleph}

parecendo entender tudo o que a professora diz? Esse, sem dúvida, é o outro estranho, que utilizamos para incluir de uma maneira cruel e fingida de preocupar-nos com ele, a ponto que ele fique "igual" aos outros 39 (trinta e nove) na sala.

Essa cena nos parece perturbadora, acontece quase todos os dias, em vários espaços escolares, é o que nos faz refletir e o que preferimos fingir que não vemos, do que nos encorajarmos de força para enxergarmos esse outro.

Segundo Skliar (2003, p. 39), "não temos, nunca, compreendido o outro. O temos, sim, massacrado, assimilado, ignorado, excluído e incluído". Esse indivíduo é sempre visto como um problema, pois, na verdade, não o vemos, estamos mais focados em normalizar tudo e todos que nos esquecemos de contemplar a completude do outro, suas possibilidades e suas identidades.

Comumente, utilizamos, nas escolas, as ideias de um grupo homogêneo, que sempre é controlado por seus professores, vigiados, obedientes, treinados e aperfeiçoados, como Foucault (1990) nos diz, docilizamos esse corpo, sempre na mesmice da escola, essa escola proíbe a diferença e proíbe o outro diferente.

A inclusão que temos hoje é uma inclusão que mascara as diferenças, que nos faz tolerar o outro, sem sequer sabermos quem é esse outro que nos é apresentado diariamente, parece que só importa que ele aprenda e se comporte como os demais, como Skliar (2006, p. 26) propõe, estamos a "construir uma metástase e não uma metamorfose educativa".

Não escutamos esse outro, suas vontades, seus desejos, seus sonhos, simplesmente o enquadramos em uma sala de aula e o observamos. Esperamos sua resposta, sem Ihe dar direito de se pensar e se conectar com sua aprendizagem, então:

Existe uma estratégia de contenção em que o outro nunca é um agente articulador ativo. O outro é citado, mencionado, iluminado, incorporado em estratégias de imagem/contra-imagem etc., mas ele nunca menciona, ele nunca pode interferir com as imagens e jogos de contraimagem estabelecidos a priori (SKLIAR, 2002, p. 91).

Contudo, é sabido que compartilhar experiências é crucial no desenvolvimento da aprendizagem, as trocas em grupo contribuem para um aprendizado rico e 


\section{RevistAleph}

significativo; todavia, se o indivíduo não for percebido nesse papel por seus pares e/ou por seus professores, ele será apenas um objeto na sala, uma coisa, algo inanimado que não estabelece trocas, e portanto, não desenvolve saberes.

Por essa razão, é necessário haver propostas de práticas pedagógicas que consigam entender e atender aos alunos, prestando atenção na singularidade de cada ser, para, desse modo, sairmos da normalidade e da mesmice dos espaços escolares para a construção das identidades.

Eu, como qualquer outro, sou fragmentos. A academia tenta fazer de nós um sujeito só. $E$ a educação também tenta fazer-nos um sujeito uniforme, coerente, consciente... acho que somos puros fragmentos. Muitos fragmentos. E o melhor que podemos fazer na vida é manter esses fragmentos sem poluição, sem contaminação, mantê-los vivos. Nunca matar um fragmento em nome de um, ou por outro, fragmento que seja mais interessante ou mais importante (SAMPAIO; ESTEBAN, 2012, p. 313).

Assim, a educação deverá perceber esse outro em suas particularidades e, ainda, permitir que cada um se faça presente, ativo e contribuinte. Em uma postura de pertencimento àquele lugar, pois, alguém o notou e o fez notável e, assim, se afirmou como pessoa, como alguém que é importante e que pode contribuir para as relações de trocas e de aprendizagens.

Elevando a discussão desse outro que chega à escola, em nossa sala de aula, e por quem temos uma obsessão, que acaba diferenciando e marcando o indivíduo como se ele estivesse errado em ser ou ter um transtorno e/ou uma deficiência. Nesse sentido, contribuímos para que a "igualdade" acabe imprimindo, nesse aluno, mais marcas de desigualdades, transformando-o em um outro específico, marcado, e nossa obsessão é transformá-lo em alguém ou algo, como se pudéssemos fabricar um novo outro.

Na prática, será exemplificada a tentativa de transformar o outro, como: anos atrás impúnhamos aos surdos a oralidade e negávamos o aprendizado em Língua de Sinais Brasileira (LIBRAS) e, quando assim o fazíamos, obrigávamos o surdo a ser (falar) como todos os outros da classe e ignorávamos sua própria identidade. 


\section{RevistAleph}

A busca permanente do eufemismo para determinar a alteridade cria formas cruéis de determinarmos e olharmos para o outro, construindo um ser invisível que habita a sala com os demais, assim "visibilidade e invisibilidade constituem mecanismos de produção da alteridade e agem simultaneamente com o nomear e/ou o deixar de nomear" (SKLIAR, 2003, p. 71).

Assim, quando, simplesmente, não vemos o outro ou ignoramos sua presença, o tornamos coisa, um ser coisificado, transferimos para ele toda nossa arrogância, nossos achismos e nossas classificações. Por isso, a inclusão na mesmidade não pa rece ser outra coisa senão o gozo eterno da alteridade. "O outro como hóspede; o centro da mesmidade; o gozo includente para a alteridade" (SKLIAR, 2003, p.71).

As questões colocadas anteriormente são discursos de uma educação colonial, marcada pela fixação de modelos de representações, de uma ordem imutável e que garante repetições. As estratégias coloniais permanecem com a obsessão pelo outro, designando a ele a relação de alteridade, produzindo discursos sem debates, sem diálogos, em um monólogo, que divulga suas próprias ideias e que se tem nesse outro e que nada mais produz, a não ser distanciamentos e exclusões.

Nesse sentido, o "politicamente correto", em que o mundo globalizado se constitui, afasta e produz maiores exclusões quando o termo "deficiente" não pode ser utilizado, como se quiséssemos expulsar o "ruim" das pessoas pela forma que a nomeamos, então já utilizamos nomenclaturas como: deficientes, portadores de necessidades educativas especiais, sujeitos com necessidades, diferentes, entre outras. Refletindo e reproduzindo um eufemismo pedagógico:

Porque senão o outro fica sendo a imagem de um outro somente da manipulação numérica, um outro mensurável, um outro obscenamente quantificável, sem rosto, sem língua, sem corpo ou mesmo com um rosto, uma língua e um corpo devidamente medidos (SKLIAR, 2003, p. 75).

Apenas nos importamos em nomeá-lo, em ossificá-lo, mas esquecemo-nos de penetrar no outro com um olhar, com suas limitações, seria esse apenas um objeto, uma imagem, um fetiche? 


\section{RevistAleph}

Então já não importa o outro da indolência, o outro da violência, o outro dependente das drogas, o outro da deficiência, o outro da infância, o outro da língua, o outro da aprendizagem, o outro inominável, o outro irredutível. Aquilo que interessa é sua medição, o outro estatistizado e o eterno à eugenia dos corpos, das almas e das mentes (SKLIAR, 2003, p. 75).

Há várias legislações que, praticamente, obrigam que esse outro entre nas escolas regulares, porém nenhuma traz, claramente, como poderão se efetivar as práticas pedagógicas de inclusão. Então, ficamos à espera daqueles que, no dia a dia, estarão com eles buscando suas identidades, relacionando o outro com os outros, não procurando tolerar, normalizar, robotizar, mas buscar uma aprendizagem por meio da escuta, da sensibilidade, do relacionamento, do afetivo. Skliar tem razão, precisamos de mudanças em educação, ou seja, é necessário haver um sistema de educação para a inclusão.

\section{Um professor que escuta}

O que a deficiência tem a nos dizer? Porque será que silenciamos o outro para que possamos falar por eles? Quem, de fato, pode falar pelo outro? Ninguém! É impressionante como ainda não aprendemos a lidar e considerar o outro através de sua alteridade, por que ainda recorremos a uma inclusão excludente?

Se pudéssemos observar a sala de aula de vários lugares, perceberíamos a dificuldade de qualquer professor ao receber um aluno com deficiência em sua sala, seja qual deficiência for. O professor, desde o mais experiente ao mais novato, sentirá que não está "preparado", e não sabe o que fazer.

Não há, neste estudo, uma intenção de fazer uma "receita de bolo", não há um modo de preparo a seguir para práticas pedagógicas inclusivas, isto, devido à diversidade e individualidade presentes no outro que chega. Portanto, faz-se necessário que o professor desenvolva uma "escuta pedagógica", que volte seu olhar a esse outro, que desenvolva uma sensibilidade única, quase que imperceptível, neutra, sem (pre) conceitos, límpida e persistente. 


\section{RevistAleph}

Skliar (2006, p. 32) afirma que "não há mudanças educativas num sentido amplo, significativo, sem um movimento da comunidade educativa que lhe outorgue sentidos e sensibilidades". Nesse sentido, não há técnicas inovadoras, saberes extraordinários a serem aprendidos para que o professor faça a inclusão acontecer, há apenas o professor e sua escuta. Entender e ouvir o outro constituem um grande passo a caminho da inclusão:

É, pois, na tensão entre o passado, presente e o futuro/presente, ou seja, entre os anseios por teorias totalizadoras/unificadoras, de um lado, e da busca de novos paradigmas que possam dar conta das singularidades e de suas contradições, de outro, que têm emergido as discussões sobre as diferenças e as igualdades (SKLIAR, s. d., p. 2).

Assim, podemos nos valer dos pensamentos de Foucault (1999), quando afirma que é necessário fazer reaparecer as vozes, as narrativas e os saberes desqualificados daqueles que foram excluídos a fim de liberá-los.

Skliar (2003) ainda critica os espaços acadêmicos e, compactuamos com seus pensamentos, quando nos faz refletir que na formação do professor há mais convencimento do que conversação. O autor encoraja os professores para o trabalho a partir da conversa/diálogo, por que incluir depende muito do que planejamos a partir das escutas.

Skliar (2003) pensa em ensinar como oferecer; assim, nesse sentido, ofereceríamos signos - como necessidade de tempo maior nas execuções das tarefas, temos de ter em mente que não há como controlar o tempo e nem tampouco o jeito do outro. Lembremo-nos do aluno do início, sua necessidade de rolar pela sala pode ser sua autorregulação, no caso de um aluno autista, e isso talvez seja necessário para o seu aprendizado; então, porque não ofertar a ele esse tempo? Esse gesto ético de conversar e conhecer esse aluno pode proporcionar-Ihe um efetivo aprendizado e uma inclusão de fato. Dessa forma:

Pensar em uma formação de um professor que escute, um professor escutador... É uma ideia muito criticada, mas é escutar para conversar, não é, escutar apenas passivamente. Não existe outra ação na educação senão escutar primeiro (SKLIAR, 2012, p. 324). 


\section{RevistAleph}

Porém, nossa formação nos treinou e nos treina para agir e falar, sem antes, ouvir o outro, o que ele traz, o que diz, assim não somos formados para a escuta.

Skliar (2003) esclarece que pequenos gestos são mais necessários e muito mais marcantes no processo de ensino-aprendizagem do que grandes manifestações. Nesse sentido, aquele professor que me ouviu, que me tocou, me deu suporte, terá muito mais envolvimento com o outro e assim poderá surtir resultados maiores e mais produtivos, visto que esses são os professores que produzem marcas significativas na aprendizagem do outro.

Não sei se a ideia dos gestos mínimos está precisando de uma teoria. Ainda não sei, por isso não posso falar nunca muito mais do que já falo sobre os gestos mínimos... Penso, todo o tempo, na vida mesmo, penso que o único lugar onde pensar esses gestos mínimos é na vida, na experiência da vida. Fico pensando: será necessária uma teoria sobre os gestos mínimos? Ou essa apelação de pensar na vida já é suficiente? Sempre pensei que poderíamos retratar muitos gestos mínimos e ...conversar sobre eles! (SKLIAR, 2012, p. 325).

Portanto, não precisamos de grandes movimentos, não são apenas os grandes pensadores, os grandes escritores que podem produzir marcas pedagógicas, qualquer professor pode tornar-se grande nesse processo de ensino-aprendizagem, quando empresta seus ouvidos a essa escuta.

\section{O outro no contexto escolar}

A escola como uma importante instituição, que promove relações sociais, em um primeiro momento, tem feito um papel cada vez mais de reproduções de significações no sentido de tornar a sociedade cada vez mais dentro de padrões de uniformidades. Seu histórico foi sempre de exclusão e de abandono.

Várias reformas educacionais já se passaram, leis já foram criadas para garantir direitos; todavia, a questão do outro diferente no espaço escolar continua caminhando para uma dicotomia entre reflexões e práticas dessas políticas educacionais dos últimos tempos. 


\section{RevistAleph}

Colocar todas as crianças na escola tornou-se uma meta governamental nos últimos anos, e acreditamos que essa política é muito importante; no entanto, na prática, não se embasa uma educação para todos, no sentido de uma educação plena, significativa, com equidades, com justiça, em que todos sejam, de fato, atendidos em suas necessidades reais.

Ouvimos, cada vez mais, um discurso de que é necessário aceitar o outro, incluir o outro diferente, porém, em que medida temos criado movimentos reais para a inclusão desse outro nos espaços escolares, para que a autonomia, a identidade, a individualidade desse outro seja assegurada, de fato, em que currículos escolares sejam pensados, na unidade desse outro que ocupa a escola e não para a mesmidade e a normalidade.

O outro já foi suficientemente massacrado. Ignorado. Silenciado. Assimilado. Industrializado. Globalizado. Cibernetizado. Protegido. Envolto. Excluído. Expulso. Incluído. Integrado. E novamente assassinado. Violentado. Obscurecido. Branqueado. Anormalizado. Excessivamente normalizado. E voltou a estar fora e a estar dentro. A viver em uma porta giratória. O outro já foi observado e nomeado o bastante como para que possamos ser tão impunes ao mencioná-lo e observá-lo novamente. O outro já foi medido demais como para que tornemos a calibrá-lo em um laboratório desapaixonado e sepulcral (SKLIAR, 2003, p. 29).

O egoísmo das pessoas, na verdade, tornou todos iguais pela mesmidade e normalidade, chegou o momento de vivermos uma nova experiência educativa que está além das leis, dos decretos, das nomenclaturas. Passou do momento de enxergarmos o outro com base no eu, centralizado no eu e como assevera Skliar (2003) a hospitalidade da escola, assim "a mesmidade da escola proíbe a diferença do outro" (p.30).

As práticas escolares, geralmente, partem da ideia de alunos hipotéticos em uma generalização de todos, apresentando, assim, uma pedagogia em um contexto mais geral para todos. De modo geral, estão todos engessados em um currículo escolar, pretendendo que todos "aprendam", não se importando muito como ocorrerá o processo ensino-aprendizagem, "o currículo ensina o quanto somos diferentes da alteridade e se esforça por encontrar algumas semelhanças grotescas" (SKLIAR, 2000, p. 25), assim, podemos dizer que parece politicamente correto ter um aluno incluído em 


\section{RevistAleph}

classe, porém, parece que a tentativa é transformar o outro em um outro específico, dentro de um padrão de normalidade.

Sendo assim, dentro dessa normalidade, dificilmente, esse outro é visto, percebido como indivíduo. Nessa perspectiva, o outro não desenvolve suas subjetividades; por isso, é preciso pensar em uma proposta pedagógica que atenda às singularidades do outro:

A educação especial conserva para si um olhar iluminista sobre a identidade da alteridade deficiente, isto é, vale-se das oposições de normalidade/anormalidade, de racionalidade/irracionalidade e de completude/incompletude como elementos centrais na produção de discursos e práticas pedagógicas. Os sujeitos são homogeneizados, infantilizados e, ao mesmo tempo, naturalizados, valendo-se de representações sobre aquilo que está faltando em seus corpos, em suas mentes, em sua linguagem etc (SKLIAR, 1999, p. 19).

Por conseguinte, esse olhar é o que exclui mais do que aquele que nem entra na escola, pois colocamos esse outro no espaço escolar e, ignorando sua presença ou tentando uma homogeneidade da turma, focamos em uma inclusão que exclui.

Skliar (1999) acredita em uma educação que seja criativa, que permita criar, que oriente para sair da mesmidade e que não construa essa mesmidade no outro. Pensando assim, a escola deveria sim ser o espaço das diferenças, pelas diferenças de pensarmos, agirmos e falarmos. Vale lembrar que as trocas no ambiente escolar são ricas em experiências do próprio ser, caracterizando suas subjetividades. Desse modo, não só os alunos, como também os professores aprenderão por meio das diferenças e trocas.

Nesse sentido, enfatizamos que a Lei de Diretrizes de Bases da Educação Nacional (LDBEN), em seu artigo $2 \stackrel{0}{ }$, dispõe sobre a obrigatoriedade da matrícula a TODOS os alunos; portanto, a escola deve se organizar para atender a TODOS independente de sua diferença, necessidade ou deficiência (BRASIL, 1996).

Desse modo, os desafios são enormes na medida em que a escola necessita assegurar e garantir a matrícula e a permanência de todos, mesmo que seja da forma como Skliar (2003) pensa "politicamente correto", com práticas homogêneas que não contemplam a individualidade. Assim, torna-se necessário rever legislações que tratem 


\section{RevistAleph}

de inclusão, mas que ainda permitem brechas segregadoras, a fim de que haja grandes mudanças na educação quanto à inclusão escolar.

Então, questionamos: de qual escola é esta que estamos falando? Qual tipo de escola é aquela que, de fato, promove a inclusão? Neste texto, não estamos tratando de apenas inserir esse outro na turma, não estamos apenas falando do "estar junto" dentro da sala, mas estamos acreditando na possibilidade de haver uma inclusão séria e verdadeira. Assim:

De fato, em muitas escolas, de muitos países, a inclusão parece estar associada precisamente com uma metáfora do abrir as portas das escolas, enquanto a exclusão teria a ver com a metáfora oposta: a dos portões fechados. Do ponto de vista ético apresenta-se uma imagem muito clara, pois "abrir" supõe "abertura", disposição política favorável à mudança. Falo de abertura enquanto uma outra disposição política do si mesmo (antes repetido, fechado) para o outro, ou seja, de um abrir-se para o que vem do outro, abrir-se para a existência do outro (SKLIAR, 2015, p. 25).

Skliar (2015) aponta três tipos de portas para a inclusão: "de portas abertas", "de portas giratórias" e "de portas com detectores de metais". As "portas abertas" referemse às instituições que já abriam suas portas a todos, aquela que deixa o sujeito entrar simplesmente. As "portas giratórias" fazem alusão a uma escola que permite a entrada do aluno, mas, ao mesmo tempo, não trabalha com esse aluno; por conseguinte, ao mesmo tempo em que inclui, exclui. E as "portas detectores de metais" seriam as escolas que, para permitirem a entrada do aluno, antes, necessitam de "diagnósticos", ou seja, solicitam laudos para que esse aluno adentre as portas da escola.

O exemplo emblemático é, a meu entender, o dos corpos: insistimos nas escolas com ideais que tentam fugir à pretensão de um corpo normal, de uma aprendizagem normal, de um comportamento normal, mas esse mundo instala ao mesmo tempo a violência, a violação, a anorexia como modos de relação; enfim, uma noção de beleza e de normalidade que põe a perder toda a potência das diferenças do humano (SKLIAR, 2019, p. 34).

Assim, percebemos que os "diferentes" parecem sempre enfrentar dificuldades para a entrada e a permanência na escola; por isso, é urgentemente e necessário 


\section{RevistAleph}

revermos nossas ações inclusivas, em uma perspectiva de relação, na qual o outro seja visto, percebido, ouvido, sentido, em um constante diálogo e em uma permanente relação democrática de amor, de escuta e de sensibilidade.

\section{Considerações finais}

Skliar (2003), em seus estudos, mostra a relevância de se pensar em uma educação para inclusão que não trabalhe com a mesmidade das escolas, que não pense no outro apenas como hóspede, nas palavras do autor "a inclusão na mesmidade não parece ser outra coisa senão o gozo eterno da alteridade. O outro como hóspede; o centro da mesmidade; o gozo includente para a alteridade" (SKLIAR, 2003, p. 71). Assim, perceber o outro como aquele que pensa, que percebe o mundo a sua volta, que não necessita que falem por ele, para que esse outro não seja apenas a imagem de outro alguém.

Importante ressaltar que não pretendemos, neste artigo, esgotar a discussão a respeito da inclusão e, principalmente, dos pensamentos do outro, haja vista acreditarmos que quanto mais discutirmos sobre o assunto, mais propagamos e contribuímos para que haja inclusão de verdade, para que o outro possa desabrochar nas e em suas diferenças.

Acreditamos em uma educação que caminha para inclusão, com lutas e também com conquistas e que devemos e podemos contribuir para a construção real da inclusão, que esse outro não seja mais fabricado no disciplinamento social, que não seja apenas corpo da docilidade, esculpido na normalidade, construindo identidades que caminhe para alteridades.

A afirmação de Skliar (2015, p. 17) "não compete a mim, e nem tampouco sou partidário de que devo dizer o que a inclusão deveria ser e reafirmo isso agora, pois esta é a principal conclusão a qual se chega" é de grande relevância para todos que se debruçam sobre a inclusão. Esse tema é muito amplo, portanto, não cabe, nesta discussão, esgotá-lo, até mesmo porque acreditamos que não é um assunto que se encerrará com tanta facilidade. Acreditamos, contudo, que, para incluir o outro, 


\title{
RevistAleph
}

devemos pensar, repensar, pensar novamente, não bastando apenas "forçar" para que todos estejam juntos em uma sala de aula ou determinar práticas ainda mais segregadoras.

É necessário conscientizar que a "educação inclusiva" tem a ver com a ideia de justiça, justo de projeto contínuo que se inicia na educação infantil e vai até a faculdade, inclusão tem a ver com direitos de ser e estar, de falar, pensar, sentir, agir e expressar. Compreender que esse direito é do outro é de suma importância para o trabalho da inclusão, o direito é propriedade de cada um, de um outro que, eticamente, deve ser considerado como anterior a nós mesmos. Para finalizar, apresentamos as seguintes reflexões de Skliar (2015):

\begin{abstract}
Entendo que o pensamento pedagógico da inclusão deveria abandonar de uma vez, e para sempre, esse tipo de obsessão pelo outro e dirigir seu pensamento para a ideia do 'estar juntos' como a questão educacional essencial. Isto quer dizer, que o pensamento pedagógico deveria retirar de seus ombros aquela permanente e insistente pergunta: quem é o outro? Assim como, as perguntas que dela derivam: o que é que ele tem e/ou de que ele carece? Por que a aprendizagem 'dele' não entra nos cânones da 'aprendizagem'? O que Ihe acontece? O que tem a família dele?... E poder pensar, como mencionei anteriormente: o que acontece, pedagogicamente, entre nós? (SKLIAR, 2015, p. 27).
\end{abstract}

Neste artigo, defendemos que incluir perpassa a ideia de "estar junto" na mesma sala, seria, na verdade, um permitir afetar e afetar-se pelo outro, esse "outro" estranho, deficiente, excluído, que pode ser eu ou ser você.

\section{Referências}

BRASIL. Lei de Diretrizes e Bases da Educação Nacional. Lei número 9394, 20 de dezembro de 1996. Acessado em http://www.planalto.gov.br/ccivil 03/leis/l9394.htm

DUSCHATZKY, Silvia; SKLIAR, Carlos. Os nomes dos outros. Educação \& Realidade, v. 25, n. 2, p. 163-177, jul./dez. 2000.

SAMPAIO, Carmem Sanches; ESTEBAN, Maria Teresa. Provocações para pensar em uma educação: outra conversa com Carlos Skliar... Revista Teias,v. 13, n. 30 p. 311-325, set./dez. 2012. 


\section{RevistAleph}

SKLIAR, Carlos. A escuta das diferenças. Porto Alegre: Mediação, 2019.

SKLIAR, Carlos. Pedagogia (improvável) da diferença: e se o outro não estivesse aí? Tradução de Giane Lessa. Rio de Janeiro: DP\&A, 2003.

SKLIAR, Carlos. Introdução - abordagens socioantropológicas em educação especial. In: SKLIAR, C (Org). Educação \& Exclusão: abordagens socioantropológicas em Educação Especial. 5. ed. Porto Alegre: Mediação, 2006. p. 7-20.

SKLIAR, Carlos. A inclusão que é "nossa" e a diferença que é do "outro". In: RODRIGUES, D. Inclusão e educação: doze olhares sobre Educação Inclusiva. São Paulo: Summus, s/d. p. 1534.

SKLIAR, Carlos. Incluir as diferenças? Sobre um problema mal formulado e uma realidade insuportável. Revista Internacional Artes de Educar, Rio de Janeiro, v. 1, n. 1, p. 13- 28, fev./maio, 2015.

SKLIAR, Carlos. A invenção e a exclusão da alteridade "deficiente" a partir dos significados da normalidade. Educação \& Realidade, v. 24, n. 1, p. 15-32, jul./dez. 1999.

SKLIAR, Carlos. Alteridades e pedagogias. Ou ... e se o outro não estava? Educação e Sociedade, Campinas, ano XXIII, n. 79, ago. 2002.

SKLIAR, Carlos; SOUZA, Regina Maria. Considerações sobre as diferenças - caminhos para se (re) pensar a educação. Disponível em: http://twww.lite.fe.unicamp.br.Acesso em: 20 jul. 2020.

SKLIAR, Carlos A educação e a pergunta pelos outros: diferença, alteridade, diversidade e o outros "outros". Ponto de Vista, Florianópolis, n. 5, p. 37-49, 2003.

SKLIAR, Carlos. Seis perguntas sobre a questão da inclusão ou de como acabar de uma vez por todas com as velhas - e novas - fronteiras em educação. Pro-posições, v. 12, n. 2-3, p. 35-36, jul./nov. 2001.

Data de envio: $14 / 07 / 2020$

Data de aceite: $27 / 11 / 2020$. 